\title{
Career progression through professional engagement: The impact of MRS student-led activities
}

\author{
Daniel Stadler, Eva Hemmer, Babak Anasori, Zachary D. Hood, and Sanjay Mathur*
}

$\mathrm{P}$ rofessional organizations focusing on strong member-society interactions play a crucial role in the broader career development of its members and volunteers. In this context, the mission of the Materials Research Society (MRS) to promote communication among the global community of materials researchers is both an opportunity and responsibility. During the past several decades, MRS has addressed this challenge with utmost priority and authenticity, evident in its worldwide visibility. In addition to the large set of activities involving key players from universities, national laboratories, government, and policymakers, long-term engagement of students and young professionals plays a central role in the core values of MRS.

As part of its mission, MRS has revitalized the roles and responsibilities of the Academic Affairs Committee (AAC), which includes five subcommittees that oversee the educational and professional needs of current and nextgeneration materials scientists. Besides offering numerous opportunities for formal career development (e.g., career workshops, mock interviews, and resume reviews), MRS has succeeded in offering personal development through wellplanned volunteering opportunities that facilitate long-term engagement of young materials scientists at the Society's meetings and enable their career progression. The subcommittees within AAC thereby help MRS to remain flexible in its action and broad in the impact, as reflected in the variety of student-led activities organized by members of the AAC and its subcommittees.

The Student Engagement Subcommittee (SESC), home to the ever-growing MRS student community, seeks to strengthen the relationship between the Society and its student members to coordinate project-based volunteer opportunities at MRS Spring and Fall Meetings. SESC encourages student reporting and outreach to spread exciting news from the world of materials through science blogging and modern forms of science communication.

While the daily life of a university science student may focus heavily on

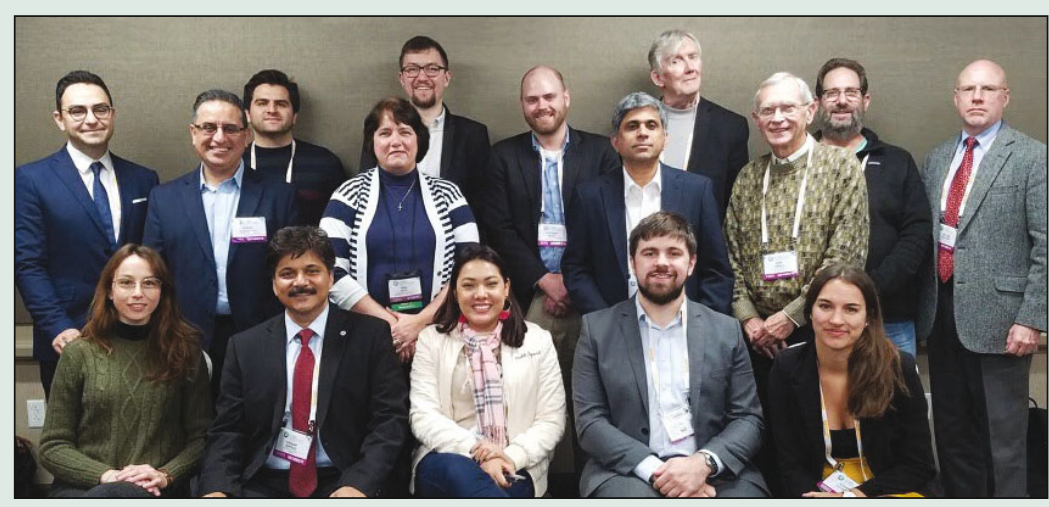

2019 MRS Fall Meeting \& Exhibit Academic Affairs Committee Meeting: (First row) Luciana d'Amone, Sanjay Mathur, Araceli Hernández-Granados, Thomas Folland, Isabel Gessner. (Second row) Babak Anasori, Husam Alshareef, Pamela Hupp, Jagjit Nanda, Ron Gibala. (Third row) Armin Vahid Mohammadi, Daniel Stadler, Zachary Hood, Bill Hammetter, Steve Yalisove, William Mullins. specialized courses at a high academic level, some may wonder how to take the next step toward applied science, product development, and commercializing. One workshop (How to Develop an Effective Proposal for User Facilities - Workshop) featured at the 2019 MRS Fall Meeting provided information to students trying to gain access to equipment and expertise only available at user facilities.

Interactions among generations create new ideas helpful in the career development of young professionals, while at the same time safeguarding the evolution of MRS. Examples of such events include Science in Video (SciVid), PowerPoint ${ }^{\mathrm{TM}}$ Karaoke, Meet Your New Faculty Candidate-Poster Session, and many more. Student-led events are not limited in their content and range from networking events to symposia. For instance, the PowerPoint Karaoke event challenges presenters to elaborate on the contents of slides that they have never seen before in a rapid-fire presentation. This student-run event was first featured at the 2019 MRS Spring Meeting, organized by a group of international volunteers, and allowed participants to communicate science in an exciting setting, while fostering student interaction and learning.

For SciVid, a competition developed by the Education Subcommittee, participants submitted videos, which are used to describe the role of materials research in the development of new devices, materials, and the analysis of algorithms, nurturing a deeper interest in materials science and engineering. After a preselection of videos, they are presented on the MRS YouTube Channel, and everybody is allowed to cast a vote. Both events are open to everyone, and meeting attendance

*Academic Affairs Committee, Materials Research Society 
is not mandatory to participate. This makes both events a fair and international challenge and helps MRS to reach out to researchers all over the world. The AAC thereby constitutes a platform in support of next-generation materials scientists who strive to network, exchange, and-most importantly - step up to become active players in the organization of materialsrelated events and programs, the motto being "By students for students."

Through a mutually rewarding interplay between the core values of MRS and membership engagement, AAC has provided new strategies for delivering innovative components toward career development of young professionals by maintaining their enthusiasm for a volunteering spirit as they transfer from students to early-career professionals. Creating an engaging environment for young professionals, the Early Career Professionals Subcommittee (ECPSC) fulfills its mission through guidance and support in all aspects of career development. This includes critical feedback in the job application process in both academia and industry, best research practices for independent scientists, effective methods to create new collaborations, strategies to present research as high-impact papers and effective presentations, and avenues to attract funding for research both as a company and as a research laboratory.

As one of the new subcommittees, ECPSC initiated its activities at the 2019 MRS Fall Meeting by organizing a new poster session entitled "Meet Your New Faculty Candidate," which was targeted at the needs of young professionals seeking faculty positions. This event provided potential faculty candidates with an opportunity to present their previous work, as well as their visions for research, teaching, and service, in a poster session while networking with recruiters and search committees. The overwhelming success of this event exceeded everyone's expectations. The event was augmented by a webinar and a panel discussion to provide opportunities for early-career candidates to learn about these career paths as well as best practices for applying for an academic job and how to effectively network with recruiters.

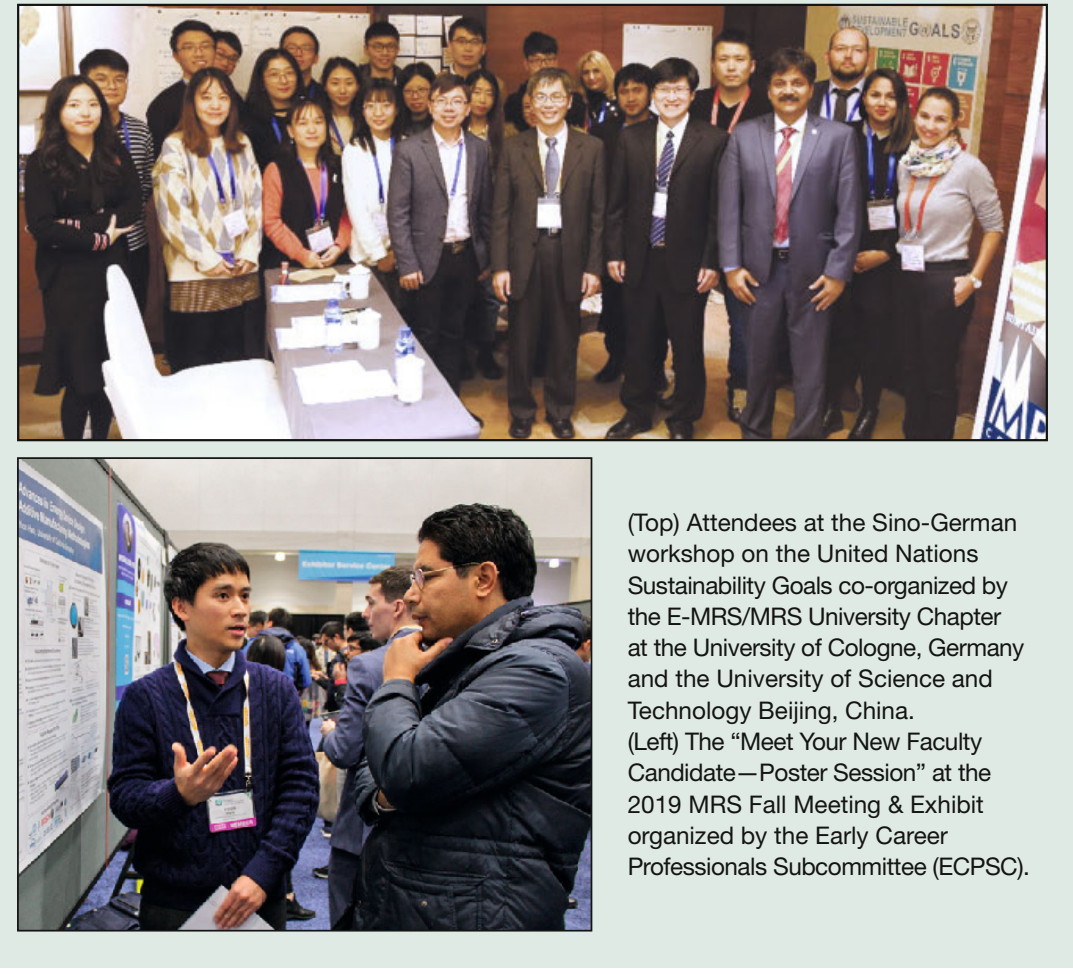

Besides the chance to organize events during MRS meetings, the AAC is affecting globalization efforts of the Society by establishing international MRS Chapters at academic institutions that offer MRS members a unique opportunity to stay engaged with the materials community and materials-related activities at their parent institutions. In addition, the MRS Foundation supports the University Chapters Special Projects Grant program, which enables University Chapter members to plan and execute specialized activities at MRS meetings. For instance, the E-MRS/MRS University Chapter at the University of Cologne successfully organized a Sino-German workshop on United Nations Sustainability Goals by collaborating with the University of Science and Technology Beijing, China.

A strong voice in ensuring quality standards in materials science and engineering education is provided by the activities of the Accreditation Subcommittee through its representation on the ABET Board of Delegates. Besides serving as an advocate for materials programs, the MRS Accreditation Subcommittee sponsors ABET accreditation training and help sessions during the Fall and Spring Meetings.
These sessions are attended by representatives of MS\&E programs, non-MS\&E programs, and international programs that have $\mathrm{ABET}$ accreditation visits scheduled or are seeking ABET accreditation. In an effort to offer online training sessions, the Accreditation Subcommittee is developing a new digital modular version to better serve the MRS membership.

A strong member-society interaction at all levels, from early stage to experienced researchers, is of central importance for any professional organ-ization striving for global excellence. Volunteer activities, pursued within AAC, are available through a diverse portfolio of events that converge into the career development of young professionals. Understanding their career needs assists the Society leadership in building, operating, and managing new early-career-focused MRS programs, and proactively encourages student and young professional interactions in MRS activities and governance. The success of student-driven activities at MRS meetings goes beyond the synergies of (social) gettogethers. These events help MRS remain at the forefront of professional societies in a diverse and changing competitive landscape. 